\title{
Potential feeding habitat of fin whales in the western Mediterranean Sea: an environmental niche model
}

\author{
Jean-Noël Druon ${ }^{1, *}$, Simone Panigada ${ }^{2}$, Léa David ${ }^{3}$, Alexandre Gannier ${ }^{4}$, \\ Pascal Mayol ${ }^{5}$, Antonella Arcangeli ${ }^{6}$, Ana Cañadas ${ }^{7,10}$, Sophie Laran ${ }^{8}$, \\ Nathalie Di Méglio ${ }^{3}$, Pauline Gauffier ${ }^{9}$ \\ ${ }^{1}$ Joint Research Centre of the European Commission, Maritime Affairs Unit, \\ Institute for the Protection and Security of the Citizen, Via Fermi, TP 051, 21027 Ispra (VA), Italy \\ ${ }^{2}$ Tethys Research Institute, c/o Acquario Civico, Viale G.B. Gadio 2, 20121 Milan, Italy \\ ${ }^{3}$ écoOcéan Institut, 18 rue des Hospices, 34090 Montpellier, France \\ ${ }^{4}$ Groupe de REcherche sur les Cétacés (GREC), BP 715, 06633 Antibes cedex, France \\ ${ }^{5}$ Souffleurs d'Ecume, Hôtel de Ville, 83470 La Celle, France \\ ${ }^{6}$ Istituto Superiore per la Protezione e la Ricerca Ambientale (ISPRA), Via Vitaliano Brancati, 48, 00144 Rome, Italy \\ ${ }^{7}$ ALNITAK, C/ Nalón 16, La Berzosa, 28240 Hoyo de Manzanares, Madrid, Spain \\ ${ }^{8}$ Centre de Recherche sur les Mammifères Marins, UMS 3462, Université de La Rochelle/CNRS, 17000 La Rochelle, France \\ ${ }^{9}$ Circé, Cabeza de Manzaneda, 3, 11390 Pelayo, Algeciras, Spain \\ ${ }^{10}$ Present address: ALNILAM Research and Conservation, Cándamo 116, 28240 Hoyo de Manzanares, Madrid, Spain
}

\begin{abstract}
The development of synoptic tools is required to derive the potential habitat of fin whales Balaenoptera physalus on a large-scale basis in the Mediterranean Sea, as the species has a largely unknown distribution and is at high risk of ship strike. We propose a foraging habitat model for fin whales in the western Mediterranean Sea relying on species ecology for the choice of predictors. The selected environmental variables are direct predictors and resource predictors available at daily and basin scales. Feeding habitat was determined mainly from the simultaneous occurrence of large oceanic fronts of satellite-derived sea-surface chlorophyll content (chl a) and temperature (SST). A specific range of surface chl a content $\left(0.11\right.$ to $\left.0.39 \mathrm{mg} \mathrm{m}^{-3}\right)$ and a minimum water depth $(92 \mathrm{~m})$ were also identified to be important regional criteria. Daily maps were calibrated and evaluated against independent sets of fin whale sightings (presence data only). Specific $\mathrm{chl}$ a fronts represented the main predictor of feeding environment; therefore, derived habitat is a potential, rather than effective, habitat, but is functionally linked to a proxy of its resource (chl a production of fronts). The model performs well, with $80 \%$ of the presence data $<9.7 \mathrm{~km}$ from the predicted potential habitat. The computed monthly, seasonal and annual maps of potential feeding habitat from 2000 to 2010 correlate, for the most part, with current knowledge on fin whale ecology. Overall, fin whale potential habitat occurs frequently during summer in dynamic areas of the general circulation, and is substantially more spread over the basin in winter. However, the results also displayed high year-to-year variations (40 to 50\%), which are essential to consider when assessing migration patterns and recommending protection and conservation measures.
\end{abstract}

KEY WORDS: Balaenoptera physalus - Potential habitat - Feeding - Mediterranean Sea · Satellite data $\cdot$ Fronts $\cdot$ Chlorophyll $a \cdot$ Environmental niche model

Resale or republication not permitted without written consent of the publisher

\section{INTRODUCTION}

The fin whale Balaenoptera physalus is the only mysticete species regularly occurring in the Mediterranean Sea (Notarbartolo di Sciara et al. 2003).
Genetic analyses have suggested the existence of a resident Mediterranean fin whale population (Bérubé et al. 1998), with evidence of some limited but recurrent gene flow between Mediterranean and North Atlantic conspecifics (Palsbøll et al. 2004). Sev- 
eral anthropogenic threats affect the Mediterranean fin whale population, with vessel strikes being one of the main causes of human-induced mortality (Panigada et al. 2006). The risk of a vessel strike is particularly severe in areas of heavy maritime traffic, such as the PELAGOS Sanctuary (ACCOBAMS 2006, David et al. 2011), where fin whales tend to concentrate in high numbers during the summer months (Gannier 1997, 2002, Notarbartolo di Sciara et al. 2003, Panigada et al. 2005, 2008, Würtz 2010). The PELAGOS Sanctuary is the first International Marine Protected Area (MPA) created in the high seas (Hoyt 2005) that aims at integrating human activities with cetacean conservation (Notarbartolo di Sciara 2007). While shipping noise is one source of disturbance, seismic airguns used for oil and gas exploration can also deter fin whales from feeding or breeding grounds (Castellote et al. 2012b). In addition, unregulated and expanding whale watching activity in the area (Airoldi et al. 1999) and the related acoustic disturbance potentially lead to unpredicted negative effects at the population level (Jahoda et al. 2003, IWC 2007).

Fin whales feed in most seas on zooplanktonic shrimps and small pelagic fish, although it appears that in the Mediterranean Sea this large cetacean mainly forages during the summer on a small euphausiacean, Meganyctyphanes norvegica (Notarbartolo di Sciara et al. 2003, Astruc 2005). The International Panel on Climate Change (IPCC 2007) and the European Environmental Agency (EEA 2008) recently issued a warning about the impact of increasing temperature on many ecological factors, including changes in phytoplankton composition, timing of blooms and the northward boundary shifts of warm-water species. This might particularly affect the distribution of the main fin whale prey, Meganyctiphanes norvegica, which is located at the southern limit of its ecological tolerance in the western Mediterranean Sea (Tarling et al. 2010). The development of robust tools to trace the distribution of the fin whale in its changing favourable habitat at the scale of the western Mediterranean Basin is therefore of primary importance to improve our understanding of the whale's ecology.

Additionally, the modelling of species distribution is a tool that can contribute to fulfilling the requirements of legislative framework and especially the Marine Strategy Framework Directive (MSFD), which represents the environmental pillar of the Integrated European Maritime Policy. The MSFD aims to achieve a good environmental status for the European Union's marine waters by 2020. 'The assessment of species also requires an integrated understanding of the distribution, extent and condition of their habitats to make sure that there is a sufficiently large habitat to maintain its population, taking into consideration any threat of deterioration or loss of such habitats' (COM_DEC 2010/477/EU).

There has been an intense research effort to describe regional habitat use and preferences of cetaceans, underlining the relationship between physical and biological variables. The considered environmental variables include sea-surface temperature (SST) (Brown \& Winn 1989, Baumgartner et al. 2001, Cañadas et al. 2005, Panigada et al. 2008); bottom topography (Baumgartner 1997, Cañadas et al. 2002, 2005, Panigada et al. 2005, Ingram et al. 2007); bathymetry, SST and chlorophyll content (Laran \& Gannier 2008); currents and frontal systems (Tynan 1998, Mendes et al. 2002, Johnston et al. 2005, Gannier \& Praca 2007); primary production cycles (Littaye et al. 2004, Panigada et al. 2008); and prey distribution (Woodley \& Gaskin 1996, Jaquet \& Gendron 2002, Baumgartner et al. 2003, Macleod et al. 2004).

The current paper presents an innovative approach for the modelling of the potential feeding habitat of fin whales in the western Mediterranean Sea by quantifying the proximity of species presence data to remotely sensed oceanic fronts of chlorophyll a $(\mathrm{chl} a)$ at a daily time scale. The originality of this work is that the potential feeding habitat is solely based on the occurrence of mesoscale productive fronts that have been identified or hypothesized to play a key role on feeding of fin whales and of other large pelagic predators (Royer et al. 2004, Druon et al. 2011). This ecologically driven approach enabled daily mapping of the fin whales' potential habitat (function of the distribution of favourable environmental conditions), but not of effective habitat (the conditions at the sighting locations) which is always difficult to produce for marine animals and especially highly migratory ones with a restricted population. The paper describes and discusses the methodology in the context of the species and area of interest. The presented results on habitat distribution and variability over a decade (2000 to 2010) highlight the necessity for making progress at a large scale. Indeed, they show that synoptic information on suitable habitat is required for implementing the MSFD within the broader Integrated Maritime Policy through the establishment of monitoring programs (by 2014), the development of conservation measures (by 2016) and the mitigation of human-induced threats on Mediterranean cetacean populations (by 2020). 


\section{INPUT DATA}

This habitat suitability model selects specific oceanic gradients observed by satellite remote sensing data at a large (or even global) scale and medium resolution (i.e. a few kilometres) to derive the potential feeding habitat of fin whales Balaenoptera physalus. The model is trained (calibrated) with an initial subset of fin whale geo-located sightings (presence data only) and then evaluated (validated) using an independent subset. Both subsets of data were collected during independent field campaigns (see Fig. 1 for the distribution of all sightings).

\section{Fin whale presence data}

The present study compiled one of the most extensive databases of precisely geo-located presence data of fin whales in the Mediterranean Sea (see the list of contributors in the 'Acknowledgements'). The database has 1451 distinct sightings in the Mediterranean Sea from 2000 to 2011, mostly between May and September. The presence data were collected with a position accuracy of $<1$ min of latitude $(<2 \mathrm{~km}$; Fig. 1). These data are mainly derived from scientific surveys with dedicated sighting protocols along fixed-line transects using ferries as platforms of observation or aboard vessels implementing the linetransect protocol (Buckland et al. 2001) and mostly travelling at speeds of 5 to 6 knots (ca. 9 to $11 \mathrm{~km} \mathrm{~h}^{-1}$ ). Other presence data were collected using less systematic data collection methods (Panigada et al. 2005) or on random routes, at about the same speed.
Several opportunistic surveys were also used (e.g. French Customs). In most cases, observational route was planned in order to search in all types of habitat (coastal, continental shelf and slope, and oceanic waters) and to accommodate for changeable weather conditions. Note that the different sampling techniques do not have an impact on the analysis, since it is based on presence data only and only location precision and date were required.

The presence data of fin whales cover most areas of the north-western Mediterranean Sea and northern Alboran Sea; however, the large majority are located in the Liguro-Provençal Basin (Fig. 1). Even though no information on behaviour was collected, the model implicitly assumed that animals would be foraging (or searching for prey) when located in the vicinity of high primary production features (presently chl a fronts).

\section{Satellite remote sensing data}

The habitat model uses the daily chl a content of SeaWiFS (from 2000 to 2010) and MODIS-Aqua sensors (from July 2002) and the SST of MODIS-Terra (from 2000) and MODIS-Aqua according to the opera-
Fig. 1. Regional seas in the western Mediterranean Sea showing the geo-located sightings of fin whale Balaenoptera physalus (crosses, $\mathrm{n}=$ 1451)

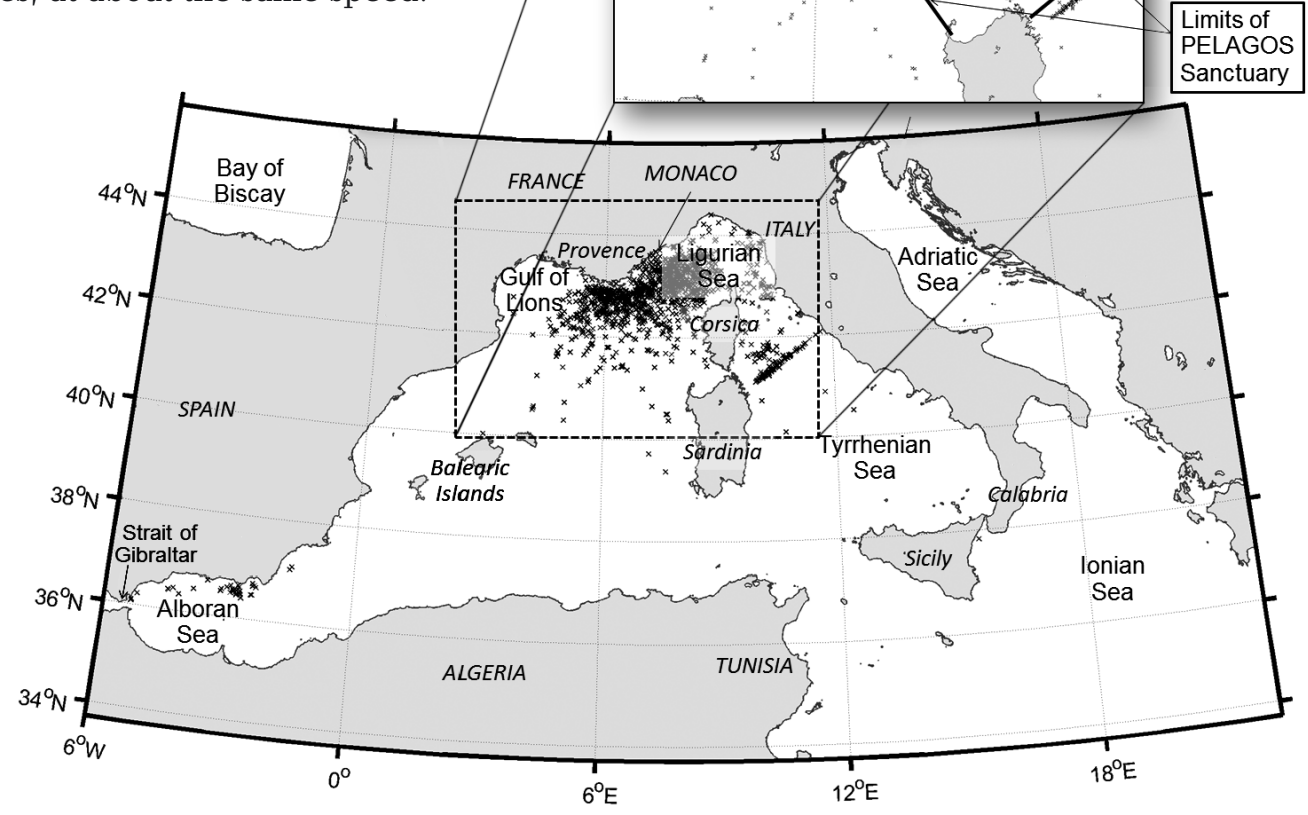


tional lifespan of these 3 satellite platforms. Chl a from MODIS-Terra was not used due to the currently low quality of the data. SST and chl a have wide coverage and both are available synchronously every day (at the scale of the processes involved, i.e. within $12 \mathrm{~h}$ ) at a medium resolution (geo-projected data at $4.6 \mathrm{~km}$ for MODIS and $9.2 \mathrm{~km}$ for SeaWiFS). SeaWiFS data were interpolated on the MODIS grid. The horizontal resolution of $4.6 \mathrm{~km}$ (NASA Standard Mapped Image) is appropriate for analysing the mesoscale oceanographic features related to fin whale behaviour, as this species can cover $>150 \mathrm{~km}$ daily (Watkins et al. 1984). One set of chl a/SST data was used at a time to derive daily habitat and the daily maps from each pair of sensors were then merged (Fig. 2).

Daily SST and chl a data were pre-processed using iterations of a median filter in order to recover missing data on the edge of valid data. This preprocessing, which represents an important gain of habitat coverage, especially in the case of dappled cloud occlusions, is described in Supplement 1 at www.int-res.com/articles/suppl/m464p289_supp. pdf. The front enhancement of daily chl $a$ and SST data is calculated with an edge-detection algorithm. Ullman \& Cornillon (2000) showed that automated edge-detection algorithms perform better than histogram methods in detecting horizontal gradients given clear viewing conditions. Spurious detections resulting from cloud masking were avoided by detecting the overlap of SST and chl a fronts. Indeed, since SST and chl $a$ are affected differently by clouds due to spectral differences (near-infrared versus visible), the detection of overlapping fronts is very likely to result from oceanic processes and not be due to atmospheric effects. In other words, the co-identification of SST and chl a fronts, which is the most selective criteria of the habitat model, is used to prevent respective cloud-edge issues (imperfect cloud mask). This edge-detection method, based on the computation of the norm of the horizontal gradient, has been successfully applied to emphasize the presence of juvenile bluefin tunas in the vicinity of chl $a$ and SST fronts in the Mediterranean Sea (Royer et al. 2004, Druon et al. 2011), a top-predator having common prey with fin whales. The calibration step quantified a minimum threshold for the norm of the horizontal gradient to remove secondary features and highlight the most productive fronts.

The night sea-surface temperature (NSST) product was selected because the skin temperature (layer of a few $\mu \mathrm{m}$ ) at night is likely to better represent the mixed layer temperature than that sensed during day time due to solar heating. Chl $a$ and NSST daily data

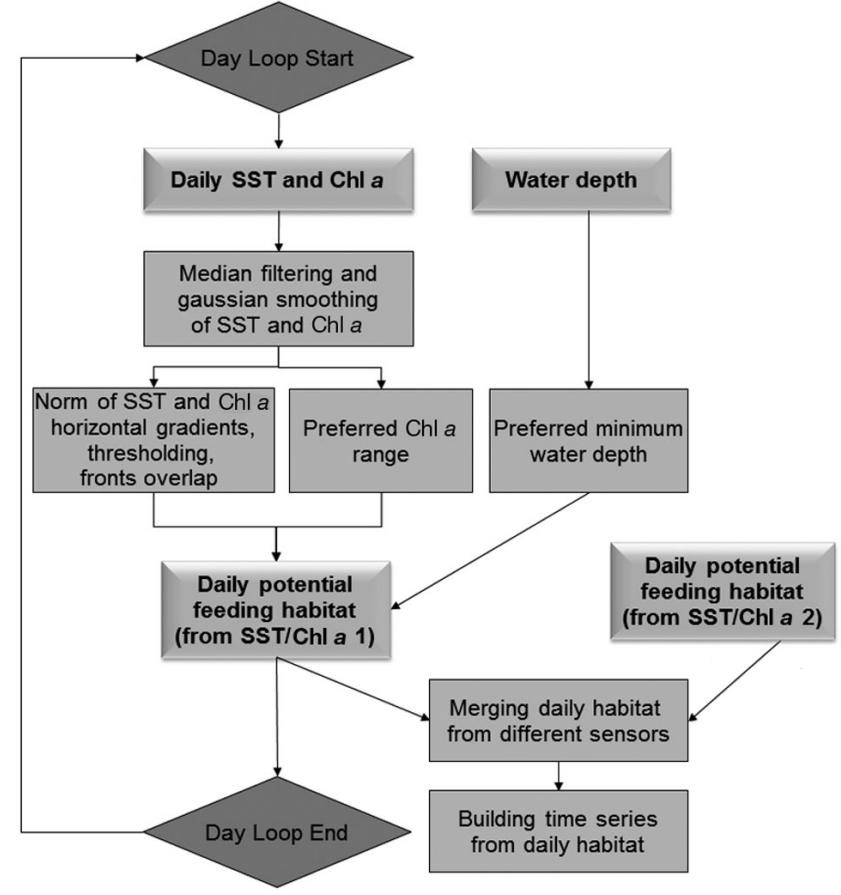

Fig. 2. Balaenoptera physalus. Flowchart of the habitat model for fin whales. Note that the model parameters linked to sea-surface temperature (SST) or chlorophyll a (chl a) data are sensor specific (see 'Satellite remote sensing data' for details)

thus show a shift in time of about $12 \mathrm{~h}$ for MODISAqua and about $9.5 \mathrm{~h}$ for SeaWiFS/MODIS-Terra. The drift of oceanographic features that might occur in that delay is, however, a lower bias compared to the gain in SST quality, since the phase velocities of currents in the study area are commonly $\leq 10 \mathrm{~km} \mathrm{~d}^{-1}$ (Sammari et al. 1995), i.e. a drift of $<1$ satellite pixel in $12 \mathrm{~h}$. The overall coverage of habitat is increased when merging the daily maps derived from both pairs of sensors in relation to differences in observing time and, thus, in cloud cover. These changes occur after a 1 to $2 \mathrm{~h}$ shift in the sensing time of chl a products at the latitude of interest for MODIS-Aqua and SeaWiFS and after a 1.5 to $2.5 \mathrm{~h}$ shift of both SST observations of MODIS-Aqua and MODIS-Terra.

\section{Water depth}

The water depth was taken from the General Bathymetric Chart of the Oceans (GEBCO) of the British Oceanographic Data Centre, with a spatial resolution of a 1 arc-minute grid (ca. $1.85 \mathrm{~km}$ at the latitude of interest; GEBCO, www.bodc.ac.uk/products/bodc products/gebco/) and interpolated to the $4.6 \mathrm{~km}$ MODIS grid. 


\section{HABITAT MODEL DESCRIPTION}

\section{Indirect, direct and resource environmental gradients}

Direct environmental gradients can have a physiological impact on organisms; conversely, indirect predictors of a species' presence refer to the gradients that influence the direct predictors. For instance, altitude influences temperature and rainfall, which have a direct effect on plant growth (Austin \& Smith 1989, Austin 2007). Direct variables were shown to be more successful predictors than indirect variables (Austin 2007). A resource predictor is defined by a component needed for the growth of an organism, such as light or nutrients for a plant. These definitions were transposed here to the marine context using a proxy of food availability (chl a fronts). Indirect predictors of fin whale Balaenoptera physalus presence are, for instance, latitude and season, which influence surface water temperature, which, in turn, strongly affect the distribution of their prey. The direct predictors are presently defined as the variables that can affect the physiology of a marine species, such as temperature, salinity, or water depth.

\section{Model structure and choice of predictors}

The structure used for habitat modelling is commonly referred to as multi-criteria evaluation, which was originally developed for terrestrial applications with a geographical information system (Carver 1991, Store \& Kangas 2001). The present multicriteria evaluation uses daily environmental marine data projected on the NASA-MODIS regular grid. The habitat criteria encompass a specific chl a range, a minimum threshold for the norm of the horizontal gradient of NSST and chl $a$, and minimum water depth (see Fig. 2). The originality of the model lies in the fact that the habitat is largely defined by the vicinity of fin whales to specific oceanic features, i.e. chl $a$ and SST fronts, which seem to be closely linked with foraging (Johnston et al. 2005, Laran \& Gannier 2008, Cotté et al. 2009). A specific chl a range at the position of these identified oceanic features is also used to detect the preferred habitat (Fig. 2). Thus, we derive a potential habitat identifying the favourable environmental conditions in the vicinity (generally less than ca. $10 \mathrm{~km}$ ) of presence data, as opposed to the effective habitat that defines the positions and/or the conditions at the sighting locations. The following sections describe in detail the choice of variables of that species niche model and how the presence data were used to optimize the parameterization.

Several studies have shown that feeding fin whales and other rorqual whales are often located in areas of thermal (Nottestad et al. 2002, Doniol-Valcroze et al. 2007) and chl a fronts (Cotté et al. 2009), where many zooplankton species are abundant (Le Fèvre 1986). The concentration of small and large zooplankton in convergence areas, such as chl a fronts, is known to attract higher trophic level predators, leading to the assemblage of a complete pelagic food web (Olson et al. 1994). Chl a fronts are thus seen as continuous productive features of organic matter efficiently assimilated by the food chain, even though their extension is restricted and chl a content is relatively low. It results that the vicinity of chlorophyll fronts together with medium chl a content are assumed to be indicative of fin whale foraging niches in the Mediterranean Sea.

The thermo-regulation of fin whales allows them to evolve in a wide range of sea temperatures (NSST at the position of presence data is from 11 to $28^{\circ} \mathrm{C}$ ), and, thus, temperature is not a priori a habitat constraint. It is indeed assumed that this range better reflects the seasonal data distribution (from April to November) than an effective temperature preference. As mentioned above, high SST values may, however, constrain the fin whale prey (southern limit of krill); we thus verified a posteriori that the highest temperature of the defined habitat is lower than or similar to the temperature range found from the presence data (of whale and thus from their prey, see 'Results'). The absolute value of SST was consequently not selected as a foraging predictor.

The relationship between maximum water depth and fin whale presence is complex since it is highly variable between seas. In the Mediterranean Sea fin whales are most commonly found in the vicinity of the general circulation currents, i.e. mostly in deep waters, but hardly ever on the inner continental shelf (Notarbartolo di Sciara et al. 2003, authors' unpubl. data). A minimum depth was thus selected as a regional criteria to remove from the preferred habitat most of the inner continental shelf, where nearly no presence has been detected to the best of our knowledge (e.g. inner shelf of the Gulf of Lions, northern Adriatic Sea), or as an event occurring once in a decade - 1997 on the inner shelf of the Gulf of Lions (Beaubrun et al. 1999).

To conclude, the criteria that were retained for the potential feeding habitat (Fig. 2) imply the estimation of 5 parameters derived from 3 environmental variables (chl $a$, SST and water depth): (1 \& 2) the overlap of the main chl $a$ and SST frontal structures defined by 
respective thresholds of the norm of the horizontal gradients, (3 \& 4) a preferred range for chl a content (i.e. upper and lower values), and (5) a minimum water depth excluding the inner continental shelf. All threshold values were defined by the calibration process.

\section{Model calibration and validation}

The calibration of the habitat model uses, as a performance estimator, the best compromise between habitat size and the shortest distances of presence data to the preferred habitat. In order to remove outlier distances caused by clouds in the vicinity of sightings (possibly masking habitat) or generated by a more complex behaviour than foraging (migration or reproduction related), the 90th percentile distance was used to calibrate and evaluate the model (see the full description of the calibration methodology in Supplement 2 at www.int-res.com/ articles/suppl/m464p289_supp.pdf). Elith et al. (2006) and Austin (2007) emphasise the need to use independent data for evaluation. The presence data was divided into 2 distinct subsets for model calibration and validation (Table 1). The calibration and evaluation data were independently collected corresponding to different field campaigns across several years as suggested by Boyce et al. (2002) (calibration data are from GIS3M 2000-2008, NATO-NURC 20022006, ISPRA 2007-2009, Alnitak 2000-2008, CETUS 2000-2009; validation data are from GREC 20002008, Tethys 2000-2007, GIS3M 2009, WWF 20102011, Souffleurs d'Écume-REPCET 2011, see details of contributors in the 'Acknowledgements'). A set of 970 fin whale sightings were selected for the calibration using SeaWiFS/MODIS-Terra from 2000 to 2010 (sensors' lifespan) among which 265 were effectively used in that process due to cloud coverage and malfunction of satellite sensors (Table 1). Similarly, 670 sightings were selected for the calibration using MODIS-Aqua from July 2002 to 2011 (sensors' lifespan) among which 299 were suitably covered by

Table 1. Balaenoptera physalus. Number of fin whale presence data available and effectively used in calibration and validation of the model. The difference between the numbers of total and used sightings is due to cloud coverage and malfunction of satellite sensors. Total number of fin whale sightings was 1451

\begin{tabular}{|lcccc|}
\hline \multirow{2}{*}{ Satellite sensor } & \multicolumn{2}{c}{ Calibration } & \multicolumn{2}{c|}{ Validation } \\
& Total & Used & Total & Used \\
\hline MODIS-Terra/SeaWiFS data (2000-2010) & 970 & 265 & 469 & 112 \\
MODIS-Aqua data (July 2002-2011) & 670 & 299 & 359 & 112 \\
\hline
\end{tabular}

satellite data in their vicinity for deriving the potential habitat. To evaluate the parameterization, we used an independent subset of 469 fin whale sightings for SeaWiFS/MODIS-Terra and 359 sightings for MODIS-Aqua. Among the validation subset, 112 sightings for both pairs of sensors were suitably covered by cloud-free satellite data (Table 1).

\section{RESULTS}

\section{Model performance}

Model calibration. Among the fin whale Balaenoptera physalus sightings which were suitably covered by satellite data in their vicinity, 30 and $32 \%$ were located within the potential feeding habitat for SeaWiFS/MODIS-Terra and MODIS-Aqua sensors, respectively (calibration histograms; Fig. 3A,C) and $80 \%$ were within 7.2 and $10.8 \mathrm{~km}$ of the habitat using the same respective sensors (Table 2). In other words, $80 \%$ of the presence data were closer than 2 pixels (of $4.6 \mathrm{~km}$ resolution) from the potential habitat. The shortest distances of fin whales to the preferred habitat (calibration histograms; Fig. 3A,C) showed a Gaussian distribution, as this would be expected of a diffusive process. Both sensor-specific parameterizations led to similar values for the minimum water depth (91.9 and $92.4 \mathrm{~m})$. We therefore selected a common value of $92 \mathrm{~m}$.

Model validation. Using the validation subset, the mean shortest distances from the preferred habitat followed the same Gaussian distribution as when using the calibration subset (Fig. 3B,D). Of the presence data, 34 and $29 \%$ were located within the potential feeding habitat for SeaWiFS/MODIS-Terra and MODIS-Aqua, respectively, while $80 \%$ of the sightings were within 11.9 and $11.1 \mathrm{~km}$, respectively (Table 2). If the 80th percentile distance obtained for validation using MODIS-Aqua is similar to that for calibration, the value resulting from the validation using SeaWiFS/MODIS-Terra is higher than that for the calibration (11.9 compared to $7.2 \mathrm{~km})$. Note, however, that this apparent lower performance from the 80th percentile distance is comparable to the distances obtained for MODIS-Aqua (10.8 and $11.1 \mathrm{~km})$. Moreover, the 50th percentile obtained for the validation using SeaWiFS/MODIS-Terra (Table 2) is the lowest among the calibration/validation results, which suggests that the 

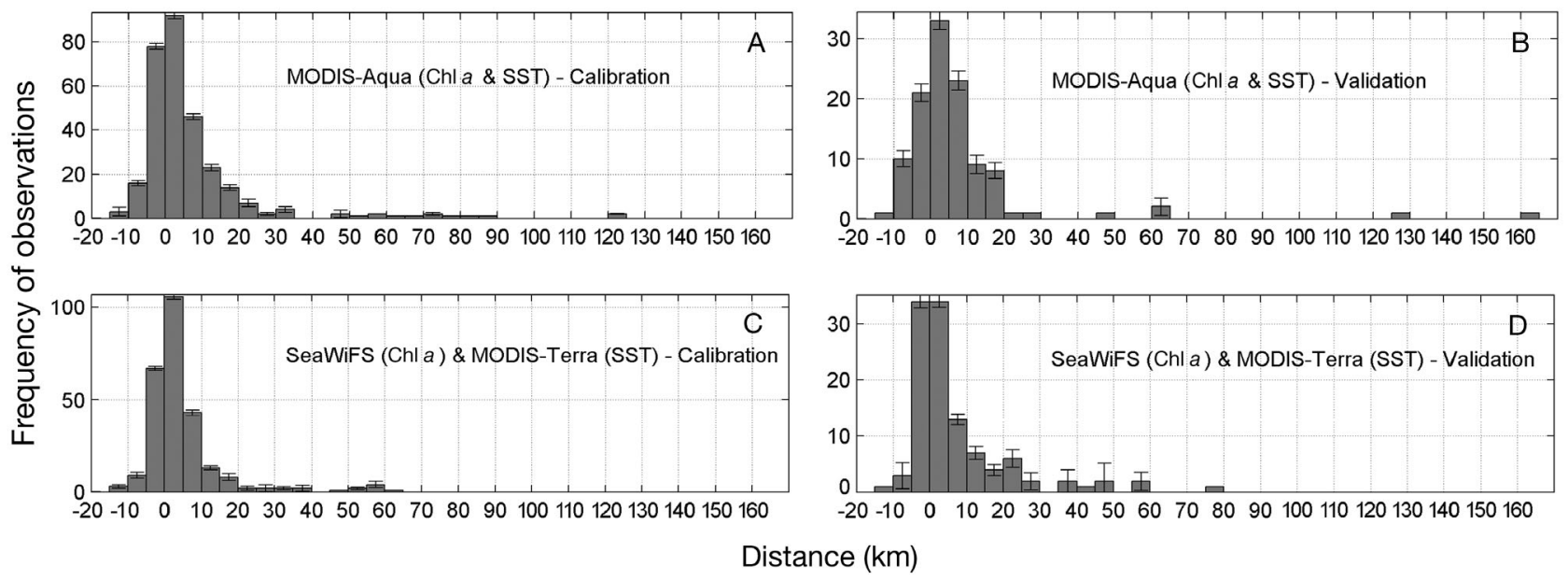

Fig. 3. Balaenoptera physalus. Distribution of relative distances of presence data (feeding-related observations) from the closest habitat boundary for the model calibration $(A, C)$ and validation $(B, D)$ using the data of MODIS-Aqua (A,B) and MODISTerra/SeaWiFS $(C, D)$, respectively. Positive values correspond to sightings outside the habitat $\left(D_{\text {out }}\right)$ and negative values to sightings inside the habitat $\left(D_{\text {in, }}\right.$ see 'Model calibration' and Fig. S1 in Supplement 2 at www.int-res.com/articles/suppl/m464 p289_supp.pdf for details). Error bars = standard deviations

variability of performance likely results from the presence datasets. Nevertheless, the overall coherence between the calibration and validation performance levels well supports the robustness of the fin whale habitat model and its parameterization.

Monthly performance levels. Monthly performance levels of the habitat model and the distribution of presence data are also presented in order to appraise the validated from the extrapolated prediction (Fig. 4). These monthly values (for all considered years) are presented for calibration and validation using the MODIS-Aqua (Fig. 4A,B, respectively) and SeaWiFS/MODIS-Terra sensors (Fig. 4C,D, respectively). Ten percent of outlier distances and presence data were removed to enable compatible results with the data effectively taken into account in the calibration (i.e. removing presumably migrating individuals and high cloud-cover sightings, see 'Model calibration and validation' and Supplement 2 for details).

Table 2. Balaenoptera physalus. The 50th and 80th percentile distances $(\mathrm{km})$ to the closest habitat for calibration and validation of the model for both pairs of satellite sensors used (MODIS-Terra/SeaWiFS and MODISAqua, see 'Model performance' and Figs. $3 \& 4$ for details)

\begin{tabular}{|lcc|}
\hline & Calibration & Validation \\
\hline MODIS-Terra/SeaWiFS data (2000-2010) & & \\
Median distance (50th percentile, km) & 2.3 & 2.2 \\
80th percentile distance (km) & 7.2 & 11.9 \\
MODIS-Aqua data (July 2002-2011) & & \\
Median distance (50th percentile, km) & 2.9 & 3.2 \\
80th percentile distance (km) & 10.8 & 11.1 \\
\hline
\end{tabular}

The model performs similarly (mean distance in the range from 2 to $5 \mathrm{~km}$ ) when the level of monthly presence data is high (i.e. in July and August on Fig. 4). Overall, a similar or better performance is observed for months with intermediate (May, June and September) or low (April, October and November) numbers of presence data.

\section{Main habitat characteristics}

Threshold values of SST and chl a gradients that characterize fronts relevant for the potential feeding habitat of fin whales were found to be $0.035^{\circ} \mathrm{C} \mathrm{km}^{-1}$ and $0.0017 \mathrm{mg} \mathrm{m}^{-3} \mathrm{~km}^{-1}$ for SeaWiFS/MODIS-Terra, respectively, and $0.034^{\circ} \mathrm{C} \mathrm{km}^{-1}$ and $0.0018 \mathrm{mg} \mathrm{m}^{-3}$ $\mathrm{km}^{-1}$ for MODIS-Aqua, respectively. The optimal range of chlorophyll concentration is from 0.11 to $0.40 \mathrm{mg} \mathrm{m}^{-3}$ for SeaWiFS/MODIS-Terra and from 0.11 to $0.39 \mathrm{mg} \mathrm{m}^{-3}$ for MODIS-Aqua. Fin whales seem indeed to preferably frequent mesotrophic waters in the western Mediterranean Sea, with $90 \%$ of sightings observed in the range from 0.10 to

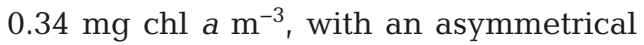
distribution towards high chl $a$ values $(\mathrm{n}=$ 1809, satellite-derived chl a estimates from both sensors; data not shown). The range found through calibration thus agrees with the values of $\mathrm{chl} a$ at the sightings' location (corresponding to the 7 th and 98th percentile values). 

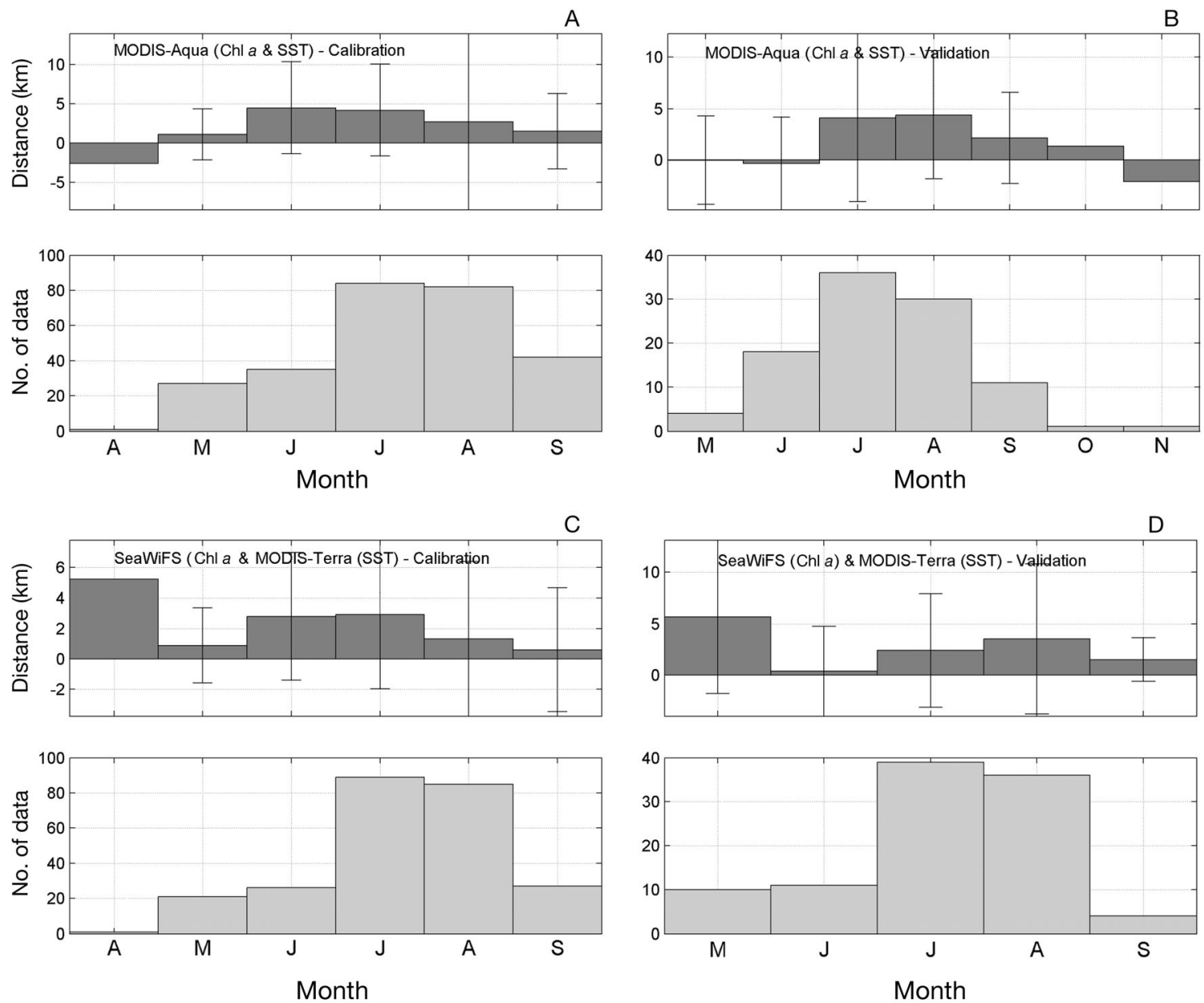

Fig. 4. Balaenoptera physalus. Upper histograms: distribution of monthly mean relative distances of presence data from the closest habitat boundary for the model calibration $(\mathrm{A}, \mathrm{C})$ and validation $(\mathrm{B}, \mathrm{D})$ using MODIS-Aqua and MODIS-Terra/SeaWiFS data, respectively; $10 \%$ of outlier values were removed to show compatible results with the calibration. Positive values correspond to sightings outside the habitat and negative values to sightings inside the habitat (see 'Monthly performance levels' and Fig. S1 in Supplement 2 for details). Error bars = standard deviations. Lower histograms: monthly mean number of presence data effectively used in both the sensor-specific calibration and validation processes; $10 \%$ of outliers were removed.

Chl a: chlorophyll $a_{\text {; }}$ SST: sea-surface temperature

If $70 \%$ of sightings in the western Mediterranean Sea were found in water depths ranging from 2100 to $2800 \mathrm{~m}(\mathrm{n}=1451$; data not shown), the remaining $30 \%$ were observed relatively homogeneously in the first $2100 \mathrm{~m}$ water depths. The observed fin whales seem, however, to avoid extended inner shelves in the western Mediterranean Sea, with a preference for deep slope areas. The inner shelves of the Adriatic Sea, the Gulf of Lions and the Catalan Sea (water depth $<92 \mathrm{~m}$ ) were excluded and most of the recurrent potential habitat $(82 \%)$ is in water depths from 200 to 2800 m, i.e. on the continental slope (Fig. 5A).

Of sightings in the western Mediterranean Sea, $90 \%$ were found in water temperatures from 17.1 to $26.8^{\circ} \mathrm{C}$, with a frequency peak ( $44 \%$ of sightings) in the range 20 to $23^{\circ} \mathrm{C}(\mathrm{n}=2198$, satellite-derived SST estimates for both sensors; data not shown). We men- tioned above that fin whale prey may be constrained by high SSTs. However, the upper temperature levels for the potential feeding habitat (2003 to 2010) are lower than at the sighting locations, with respective 95th percentile values for the satellite sets of sensors of 25.5 and $26.8^{\circ} \mathrm{C}$, which suggests that a maximum SST is unlikely to be a discriminant predictor of prey limitation in the present model.

\section{Main spatial patterns}

The potential feeding habitat of fin whales was recurrently identified ( $>25 \%$ of the time) in specific areas, such as the Alboran Sea, the shelf break area of the Gulf of Lions, the Ligurian Sea and the southern Adriatic Sea (Fig. 5A). Secondary areas of impor- 
tance for feeding appeared to be located near the coast of Algeria, in the northern Balearic Sea, the central-western Tyrrhenian Sea, in the south-east and south-west of Sicily and between eastern Sicily and Calabria. In contrast, the southern Tyrrhenian Sea and most of the central and southern part of the western Mediterranean Sea showed a low occurrence of potential habitat $(<10 \%$ of the time). The feeding habitat was concentrated on the edge of the basin in regions where the dynamics of the general circulation is high and mostly where the continental slope is steep. The feeding habitat was therefore rather continuous with a linear shape. Note, however, that not all the slopes with a high level of hydrology were selected as favourable habitat for fin whales, such as to the south of the Balearic Islands.

\section{Spatial variability at the annual scale}

Annual anomalies were computed by subtracting the occurrence of potential habitat of a given year from the multi-annual mean occurrence (2000 to 2010 period). The mean absolute anomaly over the decade was also then computed (Fig. 5B). The latter mean anomaly shows that a higher inter-annual variability occurs at the highest occurrence of favourable habitat (mostly in the eastern and central LiguroProvençal Basin), but several recurrently favourable areas also show low year-to-year variability (along the shelf break of most of the Gulf of Lions and Catalan Sea and most of the Alboran and Adriatic Seas). The annual anomalies showed that the main spatial patterns significantly changed from year-to-year (Fig. 5C-M). A positive anomaly in the northwestern Mediterranean Sea was detected in the 2000 to 2002 and 2005 to 2008 periods, with an exceptionally high occurrence in 2007, while it was mostly negative in 2003, 2004 and 2009. The north and south of the western Mediterranean Sea showed mostly opposite anomalies, especially off the Algerian coast in 2002 to 2004 (Fig. 5E -G), in 2008 and in 2010 (Fig. $5 \mathrm{~K}, \mathrm{M})$. Even if patterns varied locally, the anomaly of potential habitat was altogether low or negative at the scale of the southern Adriatic Sea in 2001 and 2005, while it was positive for 2004, 2006 and 2009. The potential feeding habitat of fin whales also showed a strong inter-annual variability at smaller scales, such as in the northern Tyrrhenian Sea (2000, 2001, 2006 and 2007 against 2002, 2003 and 2009) and in the Ligurian Sea (2000, 2005 to 2007 against 2002 to 2004 and 2009 and 2010; Fig. 5). Important year-to-year variability in that decade also took place in the Alboran Sea, in the south and east of Sicily and in the northern Ionian Sea.

\section{Spatial variability at the seasonal scale}

In addition to the inter-annual variability, the predicted feeding habitat was also highly variable among seasons, but not in all frequently favourable areas. While the north-western Mediterranean Sea and Alboran Sea showed the highest seasonal dynamics, peaking in summer and autumn, the area around Sicily and in the southern Adriatic Sea appeared more stable all year round (Fig. 6A to D). Overall, the potential habitat is less extended, but substantially more frequent (more than double), in summer and autumn than in winter and spring.

\section{Main temporal patterns of size of potential habitat}

To better analyse the habitat spread at a basin scale, we averaged the daily surface area of the western Mediterranean Sea displaying favourable feeding habitat over each month of each year between 2000 and 2010 (Fig. 7A). The seasonal cycle was well marked with the lowest habitat size in February/ March and July/August (of ca. 13\% of the western Mediterranean Sea) and the highest size in the late autumn (of $24 \%$ of the considered area), with a secondary peak in May $(17.0 \%$ of the area). Although the size of potential habitat is similar in February/March compared to July/August, it is substantially more spread so that the overall habitat occurrence is substantially higher during summer. The peak in May highlights the transition period between the winter-spread and the summer-concentrated habitats, where both regimes are present. Over the decade, the mean size of predicted potential habitat for fin whales is about $14 \%$ of the western Mediterranean Sea surface (Fig. 7B) and about $12 \%$ during summer (Fig. 7A). Year-to-year variations for each month are also important since they may reach 40 to $50 \%$ of the favourable surface area (Fig. 7A). The variability of the annual surface area between 2000 and 2010 was about 2-fold lower than the monthly values, with variations from \pm 10 to $\pm 15 \%$ (Fig. 7B). A higher habitat occurrence was observed from 2005 to 2007, compared to 2001 and 2003, and from 2008 until 2010. There was thus no specific trend in the year-to-year variations in the last decade, and the time series was too short to draw any conclusions on potential cycles from 1 to $3 \mathrm{yr}$. 

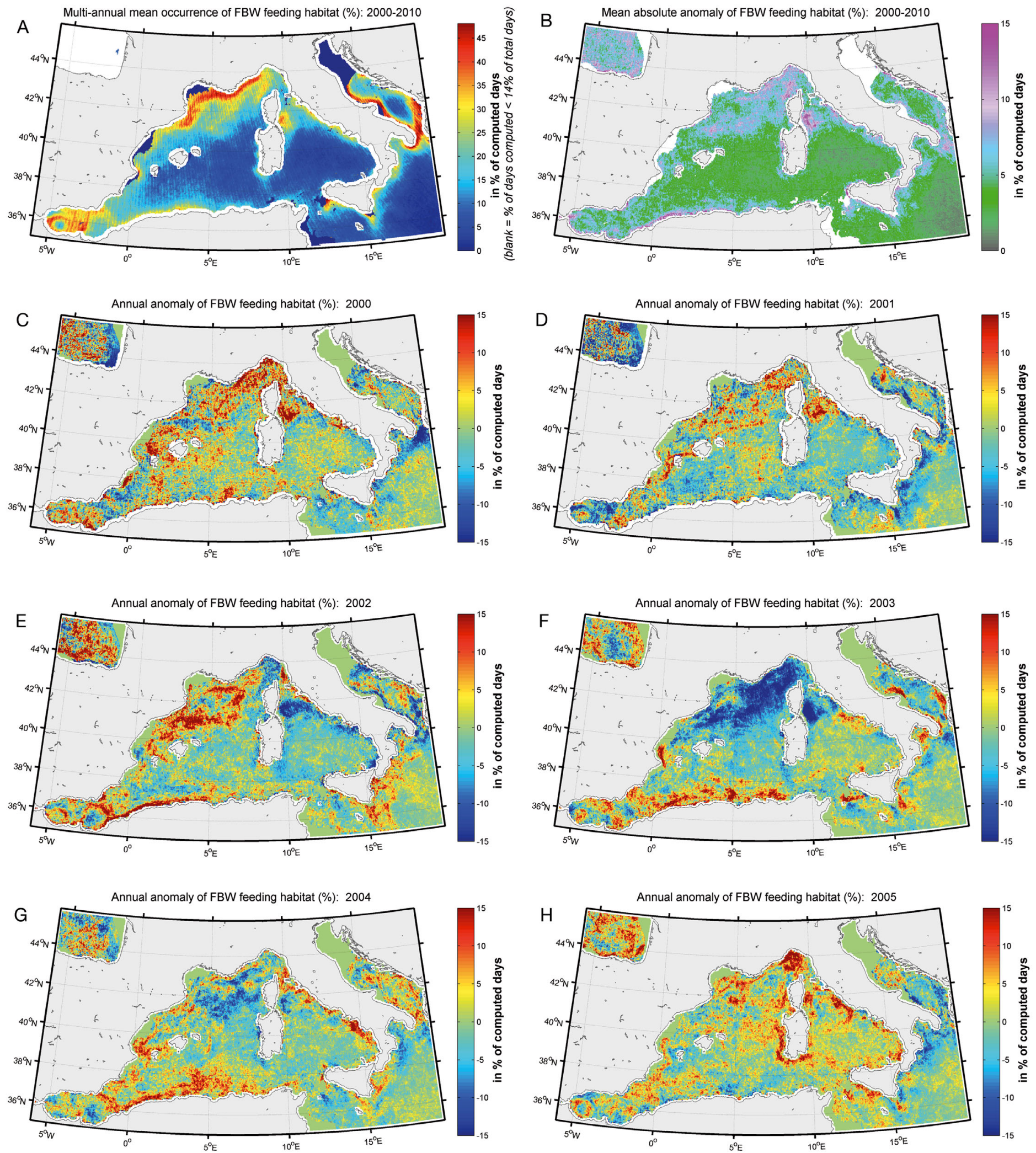

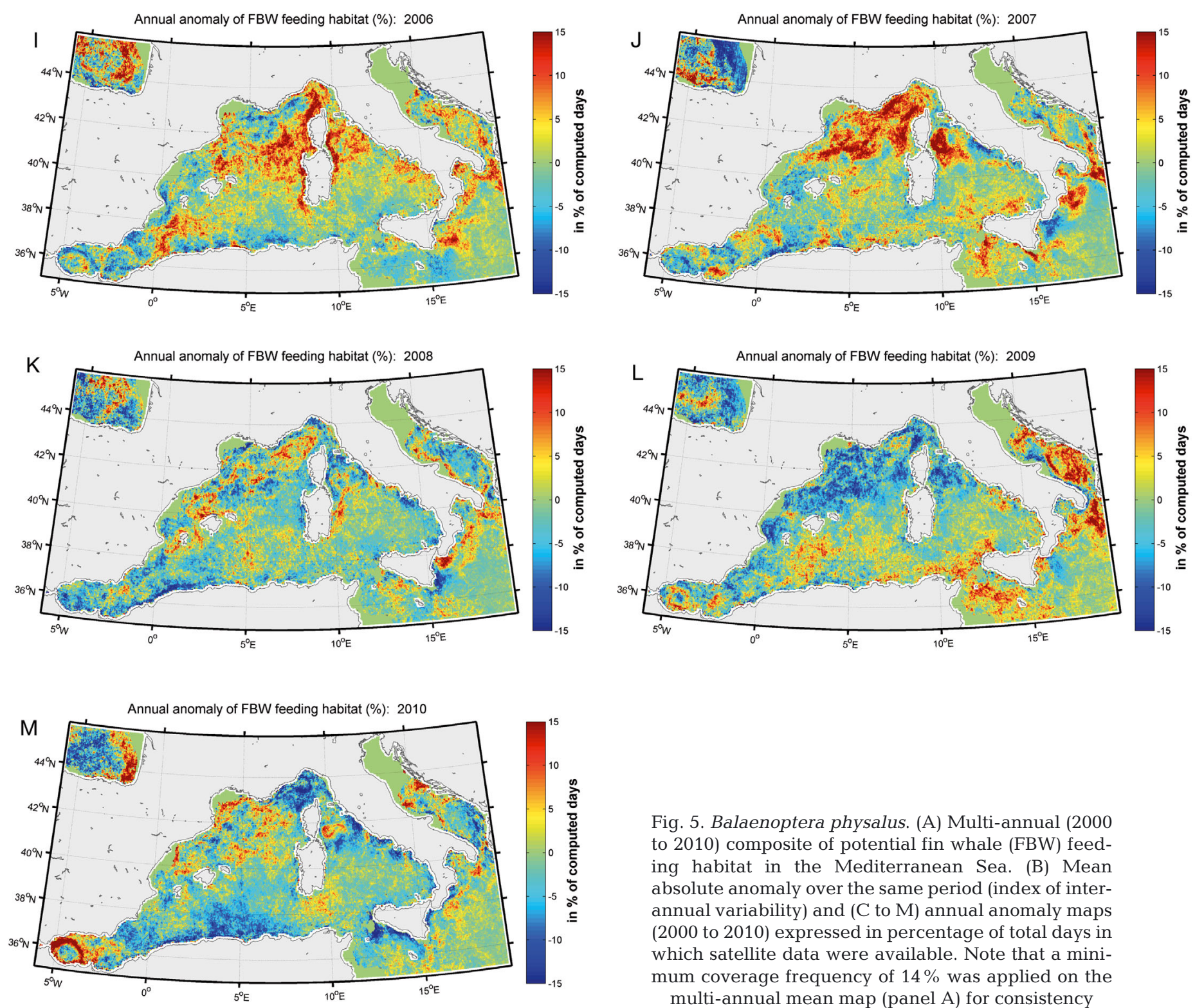

Fig. 5. Balaenoptera physalus. (A) Multi-annual (2000 to 2010) composite of potential fin whale (FBW) feeding habitat in the Mediterranean Sea. (B) Mean absolute anomaly over the same period (index of interannual variability) and ( $\mathrm{C}$ to $\mathrm{M}$ ) annual anomaly maps (2000 to 2010) expressed in percentage of total days in which satellite data were available. Note that a minimum coverage frequency of $14 \%$ was applied on the multi-annual mean map (panel A) for consistency

\section{DISCUSSION}

This approach provides a synoptic view of the potential feeding habitat of fin whales Balaenoptera physalus in the western Mediterranean Sea, as well as its spatial and temporal variations, which are important for evaluating the relevance of MPAs or a network of MPAs and for implementing protection measures to reduce anthropogenic threats such as ship strikes (Panigada et al. 2006).

\section{Selection of method and predictors}

The choice of the modelling method and environmental variables was based on knowledge of the ecology of such pelagic top-predators as fin whales, the Atlantic bluefin tuna (Druon et al. 2011), or tropical tuna species, and of food-web dynamics, with a particular focus on a proxy of secondary producers. In fact, the model of potential feeding habitat is based on the assumption that the persistence over 

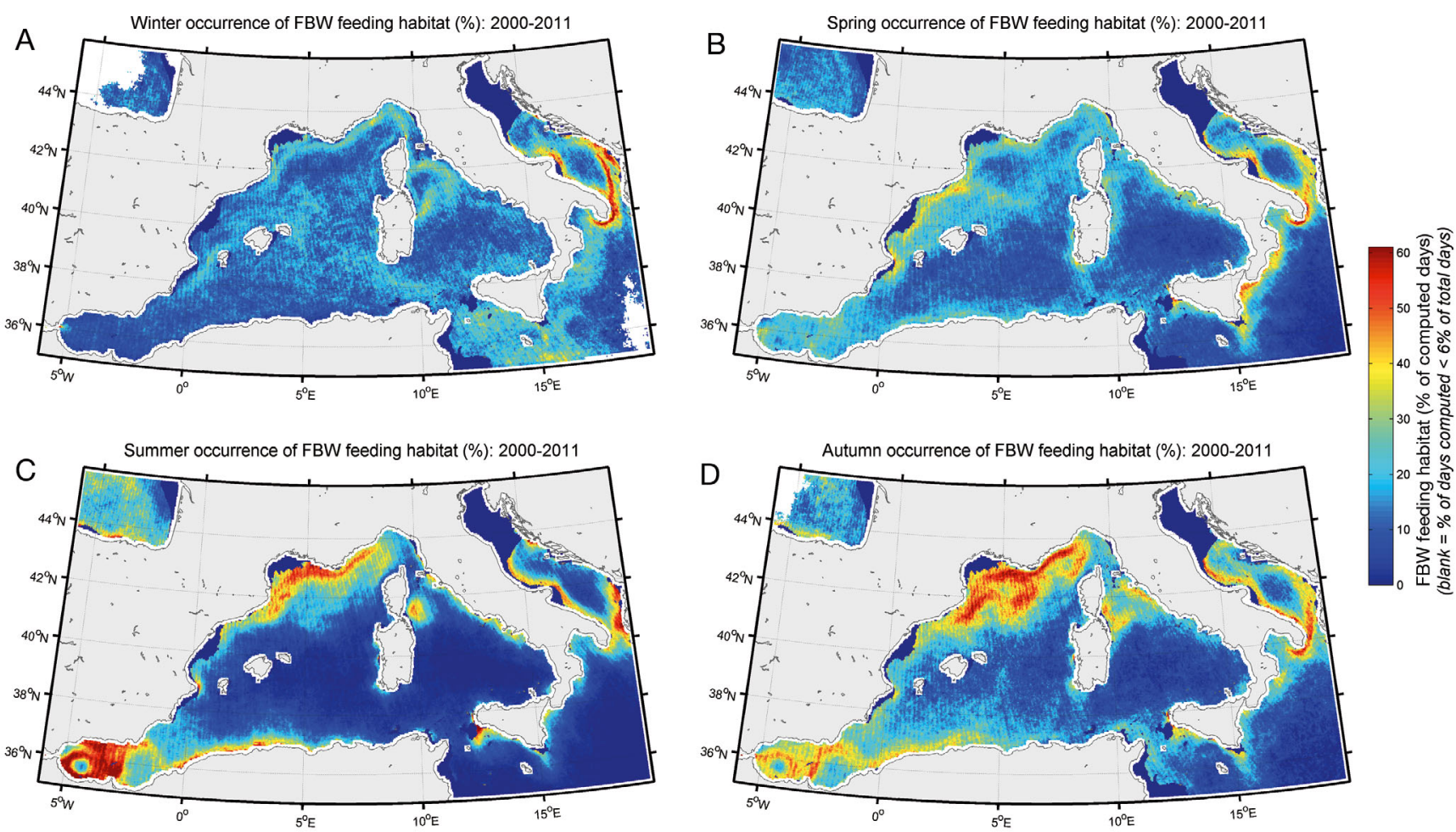

Fig. 6. Balaenoptera physalus. Seasonal composite of fin whale (FBW) feeding habitat in the Mediterranean Sea for the period 2000 to 2011: (A) winter, (B) spring, (C) summer and (D) autumn. Expressed in the percentage of total days in which satellite data were available. A minimum value of $6 \%$ of available data was applied to show consistent maps
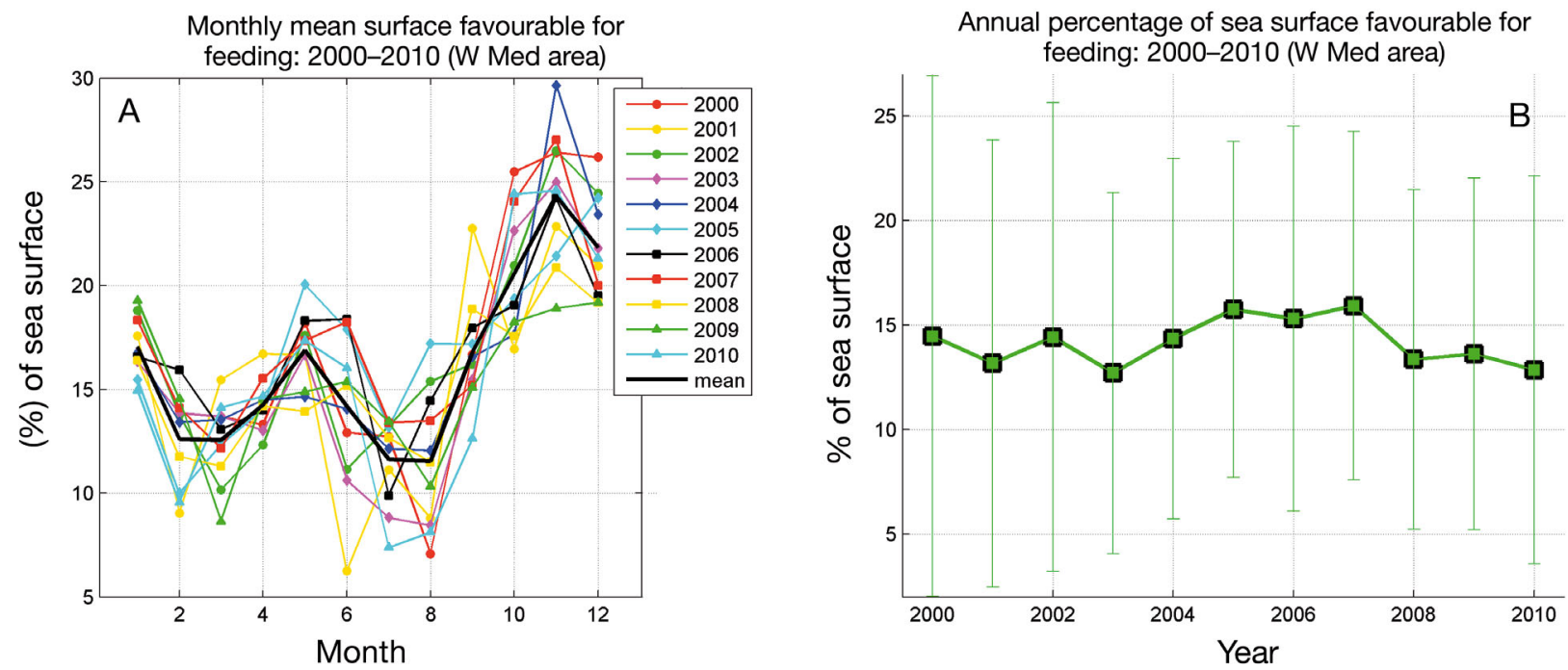

Fig. 7. Balaenoptera physalus. (A) Monthly and (B) annual mean size of potential habitat of fin whale for the 2000 to 2010 period (expressed as the mean surface of the Mediterranean Sea estimated to be favourable, in percent). Note that no frequency of potential habitat is taken into account here. In (B), error bars = standard deviation

several weeks or more of mesoscale productive fronts in a low trophic area such as the Mediterranean Sea allows a high rate of energy transfer up the food chain, notably though the growth of micro-zooplankton. This flux of energy would locally generate, via the attracted macro-zooplankton and/or forage fish, a particularly favourable niche for top-predators to feed in. The predictive capacity of chl a fronts and relatively low chl a contents for potential fin whale habitat illustrates the importance of the dynamics 
and persistence of productive fronts for pelagic ecosystems. Because the model mostly focuses on productive fronts with low chl a contents, the results suggest that, at a mesoscale, chl a horizontal gradients prevail over chl a levels regarding the energy flux across the pelagic food web of the Mediterranean Sea. It is worth noting that the sampling grids of field campaigns are often too large to properly describe the dynamics of fronts (see example in Druon et al. 2005) or the related variability of small or large zooplankton populations (see the sampling grid for the Ligurian Sea in McGehee et al. 2004).

This approach replies to the need for explicit statements about the niche theory assumed in species distribution modelling as shown by Austin (2007). The same author, in his review of species distribution models, endorses the careful selection of predictors utilizing existing knowledge of environmental processes to improve model interpretability. Valavanis et al. (2008) add that, ideally, explanatory variables should describe characteristics of the ecology of the species and indicate the presence/strength of relevant ocean processes (e.g. upwelling or fronts) by using, for example, distances of surveyed points from such processes. The resource proxy frequently available at large scales is the satellite-derived estimate of chl $a$, which precisely describes the dynamics of productive fronts. Among the other available remote variables, most are indirect predictors of high trophic areas, expressing the necessary, but often insufficient, physical conditions for enhancing primary productivity. Although fin whales do not feed on phytoplankton, surface chlorophyll content is commonly selected as a good proxy for prey availability (e.g. Littaye et al. 2004, Panigada et al. 2008), and here the remotely observed chl a level and gradients are considered to be reasonable resource predictors accessible on a wide scale and with a high return frequency. As mentioned above, SST fronts are only used to remove chl a fronts erroneously produced by non-filtered atmospheric effects. The minimum water depth, although considered a direct predictor, is seen here as a regional filter in agreement with the knowledge on species distribution. We therefore selected a limited set of direct and resource predictors (minimum water depth, chl a gradient and range) based on the ecological theory to favour both the accuracy and analysis of the prediction. Presence data were preferred over presence/ absence data since (1) absence is always difficult to assess for marine mammals; (2) the effort is low, especially if compared to the displacement capacity of fin whales; and (3) utilizing presence data only was confirmed to successfully predict species distributions
(Elith et al. 2006). Furthermore, mobile animals may not use the entire suitable habitat at any one time (Boyce et al. 2002); thus, it may be difficult to demonstrate non-use, especially in the case of small populations (ca. 3500 individuals in the western Mediterranean Sea; Forcada et al. 1996, Panigada et al. 2011). Lastly, in addition to the ecological knowledge taken into account, the spatial dimension of the model for optimizing the parameterization (distance to potential habitat as enhanced by Valavanis et al. 2008) on a daily time scale and the ability to select optimal habitat size are key predictive elements which are not present in most regression models.

\section{Model limitations and performance}

The major limitations of this methodology are cloud cover and the quantity and distribution (in time and space) of fin whale sightings. Druon (2010) has discussed the impact of cloud cover on habitat coverage in the Mediterranean Sea, with a maximum in winter and a minimum in summer. For instance, the mean seasonal coverage for daily fin whale habitat in 2006 in the western Mediterranean was about 3 times lower in winter $(10 \%)$ than in summer $(31 \%$, values using both satellite datasets). For operational use, the $3 \mathrm{~d}$ composite habitat map is therefore well covered during summer, i.e. at the peak of such humaninduced threats for fin whales as maritime traffic. The increase of habitat coverage using a second pair of satellite sensors with a 1.0 to $2.5 \mathrm{~h}$ observation timeshift was $36 \%$ for feeding habitat as a mean value for 2003 (Aulanier \& Druon 2010). Furthermore, there was little difference in habitat classification when using MODIS-Aqua and SeaWiFS/MODIS-Terra (5\% for the potential feeding habitat) which indicates that both sensors' data can be used in parallel (Aulanier \& Druon 2010). The combination of several satellite sensors with independent calibrations appears to efficiently circumvent the difficulties induced by cloud cover from spring to autumn. However, the lack of fin whale sightings and the high cloud coverage during winter in the western Mediterranean Sea still represent the major technical limitations of our approach.

The boundary between the core and marginal habitat is often expressed in stochastic models as a probability of occurrence. The daily transition in the present model is sharp and optimized by a trade-off between habitat size and distance of sightings to the preferred habitat. Indeed, its size needed to be set, since the potential habitat is based on specific oceanic fronts in the vicinity of presence data and not 
directly at the location of presence data. Habitat size was defined by the $W_{\mathrm{f}}$ parameter in the cost function $f_{\text {min }}$ (see Supplement 2 for details). This parameter is likely to include several species characteristics, such as the distance covered per time unit, the quantity and quality of environmental information collected and the behaviour. Therefore, this parameter may vary between species of different size and trophic rank in the food web. The $W_{\mathrm{f}}$ values found to optimize the habitat size for fin whales were similar to the value found for juvenile bluefin tunas (Druon et al. 2011), suggesting that these 2 top predators have similar displacement capacities to search for their prey in the Mediterranean Sea. If the minimum chl a value obtained for the habitat of both species is similar, the maximum chl a value for fin whale $(0.34 \mathrm{mg}$ $\mathrm{m}^{-3}$ ) is slightly lower than for juvenile bluefin tuna $\left(0.41 \mathrm{mg} \mathrm{m}^{-3}\right)$. These results suggest that both species mostly exploit the same niche for feeding in the western Mediterranean Sea, but fin whales also explore slightly less turbid fronts, presumably in relation to prey differences and foraging strategy. It was suggested above that high SST levels might constrain some types of fin whale prey such as the northern krill. While not refuting the temperature limitation, the higher level of maximum SST observed at the location of fin whale presence data compared to the computed habitat indicates, however, that the use of a maximum temperature value as a predictor would have led to the same model performance. Indeed, chl a fronts are mostly impeded by the important heating of surface waters, for example during the heat wave of summer 2003 in western and central Europe (Rebetez et al. 2006, see the negative anomaly in the north of the western Mediterranean Sea; Fig. 5F). This example shows that the choice of direct and functionally linked predictors allows us to reduce model complexity while increasing interpretability.

In addition to its simplicity, the model is also characterized by the primary use of relative data (computation of spatial gradients) which contains the most valuable information of Earth observation data. The absolute values are indeed a minor constraint in the model and are less consistent for a given satellite sensor, due to atmospheric effects, and between sensors, due to intrinsic characteristics. The present model performs well in areas where both satellite data and fin whale sightings are available. Indeed, (1) a large fraction of fin whale sightings are in the vicinity of the potential habitat (overall, $80 \%$ of presence data are within $9.7 \mathrm{~km}$ of the potential habitat, $\mathrm{n}$ = 788), (2) the general Gaussian shape of the histograms of distances between sightings and the habitat boundary is as expected from a diffusive process, (3) the validation with an independent dataset supports the robustness of the model calibration, and (4) the model shows similar performance levels from May to September (Fig. 4). Furthermore, the potential feeding habitat identified in the western Mediterranean Sea is mostly in good agreement with the general knowledge of this species in the area (Notarbartolo di Sciara et al. 2003, Dubroca et al. 2004, Panigada et al. 2005, Marini \& Arcangeli 2010, Di Fulvio et al. in press) and predicted habitat using a stochastic approach (Monestiez et al. 2006, Laran \& Gannier 2008). The spatial resolution of $4.6 \mathrm{~km}$ appears to be appropriate for the detection of oceanic features of importance for the foraging of fin whales.

The output that is not fully supported by current knowledge mostly concerns the high occurrence of potential feeding habitat in the southern Adriatic Sea all-year-round and the Alboran Sea in summer and autumn (Fig. 6), which were both classified by Notarbartolo di Sciara et al. (2003) as regions of intermediate importance. The Alboran Sea was recently suggested to be a wintering ground for the north-east North Atlantic population (Castellote et al. 2012a). This is consistent with the observation of fin whales migrating through the Strait of Gibraltar towards the Mediterranean Sea in November/December and back from May to July (Gauffier et al. 2009, 2011). On the other hand, tagging experiments have shown that feeding fin whales in the north-western Mediterranean Sea may be year-round residents or migrate to the Atlantic Ocean crossing the Alboran Sea (Bentaleb et al. 2011). The abundance of fin whales in the Alboran Sea is, however, low, especially in the northern part where observation effort was substantial in the past 2 decades. There is an apparent absence in the Alboran Sea of preferred prey during summer, i.e. northern krill (Casanova 1970), and, to our knowledge, no feeding behaviour has been observed, nor documentation published on available prey, which suggests that this area may simply be a corridor for fin whales. The preferred habitat in the Alboran Sea in summer could thus represent a false positive result of the model related to the presence of different macro-zooplankton populations from those preferred, although there is insufficient evidence to make definitive conclusions. Indeed, SST values during summer are similar to those in the Ligurian Sea so that temperature is not the limiting growth factor for northern krill in the Alboran Sea. Moreover, in agreement with the fin whale sightings, northern krill were collected in the Alboran Sea during winter (Zane \& Patarnello 2000) and were also found in the northern part in spring as an impor- 
tant portion of the stomach contents of bentho-pelagic shrimps (Fanelli \& Cartes 2004).

When focusing on presence data which are substantially distant from the potential habitat (above $50 \mathrm{~km}$ ), 10 among the 23 outlier values (for both calibration and validation and both satellite datasets; see Fig. 3) were likely caused by relatively low satellitedata coverage (25 to $60 \%$ ) in their vicinity $(50 \mathrm{~km}$ radius). Among the 13 other cases with higher satellite coverage, 6 outlier distances corresponded to a single group of whales travelling linearly for $>76 \mathrm{~km}$ on the same day (27 August 2003), suggesting migration behaviour. Of the 7 remaining outlier distances, 5 were mainly located west of Sardinia. This area represents a lower density of observations compared to the Ligurian Sea and outer Gulf of Lions (Fig. 1). The authors suggest that the distribution of presence data may have influenced the calibration process and led to slightly weaker performance in areas where observations were less abundant. However, these outliers represent $<1 \%$ of the sightings ( 7 out of 788 ) and correspond to areas where the limits between favourable and unfavourable environmental conditions are more frequent. The general consistency of the model agrees with current knowledge, and presence data in the vicinity of productive mesoscale features clearly indicates their important role in the foraging of fin whales.

\section{Distribution and migration of fin whales}

Although the model results show that potential habitat is seasonally recurrent in some areas, its high inter-annual variability, especially in the LiguroProvençal basin (Fig. 5B), requires fin whales to rapidly cover large distances searching for food. This is attested to by the absence of recurrent observations from year-to-year at the regional scale. The fin whale population is therefore likely to follow seasonal patterns of recurrent favourable habitats, but with an important ability for spotting productive areas at the scale of $10 \mathrm{~s}$ to $100 \mathrm{~s}$ of kilometres. The present results would tend to support the hypothesis that the fin whale population concentrates in summer and autumn in a spatially restricted feeding habitat and spreads in winter and spring, notably to the south and east of Sicily, in agreement with current knowledge (Notarbartolo di Sciara et al. 2003, Aïssi et al. 2008, Bentaleb et al. 2011). Due to low sighting capability, our perception of the population distribution is likely to be limited to areas of high densities. Observation effort is indeed particularly scarce in the lowdensity areas of most of the south-western Mediter- ranean Sea (e.g. the southern Alboran Sea being a medium-density area) and during winter and spring periods (see Aïssi et al. 2008 for a rare example of a large-scale campaign), i.e. where and when the encounter rate is particularly low. It would be of great interest to dedicate observation effort to environments of low densities, perhaps assisted by habitat maps in near-real time, in order to explore the population distribution all-year-round and potential migration patterns. Similarly, particular observation effort should focus on the Strait of Gibraltar area to further characterize this observed cross-basin route (Gauffier et al. 2009, 2011) and to evaluate the mixing of populations. If the seasonal migration of Atlantic fin whales through the Strait of Gibraltar is established, it could be assumed that at least 2 subpopulations of fin whales may co-exist in the southern Mediterranean Sea from December to April/May (Castellote et al. 2012a), presumably in relation with breeding (Notarbartolo di Sciara et al. 2003).

\section{Implications for species conservation}

Although the results were only validated in the Liguro-Provençal basin during spring and summer; and they should thus be considered with caution, the model provided 2 important results in terms of management and conservation. For the first time, a synoptic view of potential feeding habitat and its variability are proposed at the scale of the whole western Mediterranean Sea, based on $10 \mathrm{yr}$ of in situ and satellite-remote-sensing data, although most of the presence data is from the north-western part of the basin. The recurrent favourable foraging grounds provide a strong basis for proposing and adopting protection and mitigation measures at least in the area of the PELAGOS sanctuary. These measures should preferably be dynamic, since most of the recurrent potential habitat has also been shown to be the most variable from year-to-year (Fig. 5B). Besides the variability over a decade, the model results show the capacity of the near-real-time maps to feed, on a daily basis, operational tools or measures for improving species protection and conservation. Fin whales face several anthropogenic threats, such as ship strikes from large commercial vessels, with a potentially significant impact on the species in the Mediterranean Sea (Laist et al. 2001, ACCOBAMS 2006, Panigada et al. 2010). David et al. (2011) and David \& Di-Méglio (2011) highlight areas of high collision risk in summer in the most favourable feeding habitat pointed out in the present study, i.e. the north-western part of 
the Mediterranean Sea. New routes will be launched and oil prospecting and military exercises will likely increase in this area generating further disturbances through noise and pollution. The maps produced by the model could therefore be used to:

1. Analyse the impact of present and future distributions of human activities, such as maritime traffic, to mitigate the risk of ship strikes, or seismic methods of prospecting, and define periods and areas where disturbances should be avoided. These protection measures could suitably be imbedded in the European Integrated Maritime Policy.

2. Increase protection measures in near-real time, providing information to maritime stakeholders on potential areas of fin whale presence, especially in cases of observed high abundance. This could provide an important contribution to the definition of dynamic measures of protection in space and time. The maps produced by the model could, for instance, be integrated into real-time alerting systems of whale positions on board large commercial vessels, to suggest alternative routes avoiding potential whale presence. Such an approach is foreseen with the REPCET system (real-time plotting of cetaceans, www.repcet.com/en), which transmits whale sightings into real-time to the participating fleet (Mayol et al. 2008, Di-Méglio et al. 2010).

3. Detect potentially favourable habitats where no animal presence is found despite observation effort, highlighting a non-use of habitat presumably in relation with anthropogenic disturbances.

4. Follow the habitat change at both annual and climate time scales, allowing the set-up of a long-term monitoring system at the species level.

Satellite remote sensing of the ocean surface is a powerful observational tool when fully exploited by an interdisciplinary research team. It has the potential to provide key pieces of information at a wide range of spatial and temporal scales for the sustainable management of marine ecosystems, including its fisheries component (Chassot et al. 2011, Stuart et al. 2011).

Acknowledgements. The authors thank the Ocean Biology Processing Group (Code 614.2) at the GSFC, Greenbelt, Maryland 20771, USA, for the efficient production and distribution of ocean colour and sea-surface temperature data. The authors are particularly grateful to all research groups that recorded fin whale sightings over the years, namely GIS-3M (CRC-Marineland, WWF-France, Souffleurs d'Écume, écoOcean Institut, GECEM and their partners - Swiss Cetacean Society, Cybelle Planète, Fondation Nicolas Hulot and Participe Futur), NATO-NURC, GREC, ISPRA, Accademia del Leviatano, Tethys Research Institute, CETUS, Alnitak, SOS Grand Bleu, BDSF, Regard du Vivant and French Customs. We are also particularly thankful to Rob Scott and Eoin Mac Aoidh for editing the paper.

\section{LITERATURE CITED}

ACCOBAMS (2006) Report of the joint ACCOBAMS/Pelagos workshop on large whale ship strikes in the Mediterranean Sea. Weinrich M, Panigada S, Guinet C (eds) 14-15 November 2005, Monaco

Airoldi S, Azzellino A, Nani B, Ballardini M, Bastoni C, Notarbartolo di Sciara G, Sturlese A (1999) Whalewatching in Italy: results of the first three years of activity. Eur Res Cetaceans [Abstracts] 13:153-156

Aïssi M, Celona A, Comparetto G, Mangano R, Würtz M, Moulins A (2008) Large-scale seasonal distribution of fin whales (Balaenoptera physalus) in the central Mediterranean Sea. J Mar Biol Assoc UK 88:1253-1261

Astruc G (2005) Exploitation des chaines trophiques marines de Méditerranée par les populations de cétacés. Mémoire de diplôme, Ecole Pratique des Hautes Etudes

Aulanier F, Druon JN (2010) Habitat modelling of marine species derived from satellite data: technical aspects. European Commission EUR 24498 EN-Scientific and technical research series - Joint Research Centre. Publications Office of the European Union, Luxembourg

Austin M (2007) Species distribution models and ecological theory: a critical assessment and some possible new approaches. Ecol Modell 200:1-19

Austin M, Smith T (1989) A new model for the continuum concept. Plant Ecol 83:35-47

Baumgartner MF (1997) The distribution of Risso's dolphin (Grampus griseus) with respect to the physiography of the northern Gulf of Mexico. Mar Mamm Sci 13:614-638

Baumgartner MF, Mullin KD, May LN, Leming TD (2001) Cetacean habitats in the northern Gulf of Mexico. Fish Bull 99:219-239

Baumgartner MF, Cole TVN, Campbell RG, Teegarden GJ, Durbin EG (2003) Associations between North Atlantic right whales and their prey, Calanus finmarchicus, over diel and tidal time scales. Mar Ecol Prog Ser 264:155-166

Beaubrun P, David L, Fabre J, Muller M (1999) Exceptional appearance of fin whales (Balaenoptera physalus), during the summer 1997, in the Gulf of Lion (French Mediterranean coast). Eur Res Cetaceans 13:162-164

> Bentaleb I, Martin C, Vrac M, Mate B and others (2011) Foraging ecology of Mediterranean fin whales in a changing environment elucidated by satellite tracking and baleen plate stable isotopes. Mar Ecol Prog Ser 438:285-302

Bérubé M, Aguilar A, Dendanto D, Larsen F, Notarbartolo di Sciara G and others (1998) Population genetic structure of North Atlantic, Mediterranean Sea and Sea of Cortez fin whales, Balaenoptera physalus (Linnaeus, 1758): analysis of mitochondrial and nuclear loci. Mol Ecol 7: 585-599

> Boyce MS, Vernier PR, Nielsen SE, Schmiegelow FKA (2002) Evaluating resource selection functions. Ecol Modell 157:281-300

$>$ Brown CW, Winn HE (1989) Relationship between the distribution pattern of right whales, Eubalaena glacialis, and satellite-derived sea surface thermal structure in the Great South Channel. Cont Shelf Res 9:247-260

Buckland ST, Anderson DR, Burnham KP, Laake JL, Borchers D (2001) Introduction to distance sampling: estimating abundance of biological populations. Oxford Univ. Press, Oxford

Cañadas A, Sagarminaga R, García-Tiscar S (2002) Cetacean distribution related with depth and slope in the Mediterranean waters off southern Spain. Deep-Sea Res I 49:2053-2073 
Cañadas A, Sagarminaga R, De Stephanis R, Urquiola E, Hammond PS (2005) Habitat preference modelling as a conservation tool: proposals for marine protected areas for cetaceans in southern Spanish waters. Aquat Conserv 15:495-521

Carver SJ (1991) Integrating multi-criteria evaluation with geographical information systems. Int J Geogr Inf Sci 5: 321-339

Casanova B (1970) Répartition bathymétrique des euphausiacés dans le bassin occidental de la Méditerranée. Rev Trav Inst Pêches Marit 34:205-219

> Castellote M, Clark CW, Lammers MO (2012a) Fin whale (Balaenoptera physalus) population identity in the western Mediterranean Sea. Mar Mamm Sci 28:325-344

Castellote M, Clark CW, Lammers MO (2012b) Acoustic and behavioural changes by fin whales (Balaenoptera physalus) in response to shipping and airgun noise. Biol Conserv 147:115-122

> Chassot E, Bonhommeau S, Reygondeau G, Nieto K and others (2011) Satellite remote sensing for an ecosystem approach to fisheries management. ICES J Mar Sci 68: 651-666

Cotté C, Guinet C, Taupier-Letage I, Mate B, Petiau E (2009) Scale-dependent habitat use by a large free-ranging predator, the Mediterranean fin whale. Deep-Sea Res I 56:801-811

David L, Di-Méglio N (2010) Prévention des collisions entre navires et grands cétacés (rorqual et cachalot). Rapport Final du Programme de recherche 2007/2009 de PELAGOS France. GIS 3M / EcoOcéan Institut

David L, Alleaume S, Guinet C (2011) Evaluation of the potential of collision between fin whales and maritime traffic in the north-western Mediterranean Sea in summer, and mitigation solutions. J Mar Anim Ecol 4:17-28

Di Méglio N, David L, Capoulade F, Gambaiani D, Mayol P, McKenzie C, McKenzie E, Schneider M (2010) Synthèse des connaissances sur l'impact du trafic maritime. Report from GIS3M (Groupement d'Intérêt Scientifique Mammifères Marins de Méditerranée) for PELAGOS France, p 351

> Doniol-Valcroze T, Berteaux D, Larouche P, Sears R (2007) Influence of thermal fronts on habitat selection by four rorqual whale species in the Gulf of St. Lawrence. Mar Ecol Prog Ser 335:207-216

> Druon JN (2010) Habitat mapping of the Atlantic bluefin tuna derived from satellite data: its potential as a tool for the sustainable management of pelagic fisheries. Mar Policy 34:293-297

Druon JN, Loyer S, Gohin F (2005) Scaling of coastal phytoplankton features by optical remote sensors: comparison with a regional ecosystem model. Int J Remote Sens 26: 4421-4444

> Druon JN, Fromentin JM, Aulanier F, Heikkonen J (2011) Potential feeding and spawning habitats of bluefin tuna in the Mediterranean Sea. Mar Ecol Prog Ser 439:223-240

Dubroca L, André JM, Beaubrun P, Bonnin E and others (2004) Summer fin whales (Balaenoptera physalus) distribution in relation to oceanographic conditions: implications for conservation. In: CIESM workshop monographs. CIESM, Monaco, p 77-84

EEA (European Environment Agency) (2008) Impacts of Europe's changing climate-2008 indicator based assessment. EEA, Copenhagen

Elith J, Graham CH, Anderson RP, Dudik M and others (2006) Novel methods improve prediction of species' distributions from occurrence data. Ecography 29:129-151
Fanelli E, Cartes JE (2004) Feeding habits of pandalid shrimps in the Alboran Sea (SW Mediterranean): influence of biological and environmental factors. Mar Ecol Prog Ser 280:227-238

> Forcada J, Aguilar A, Hammond P, Pastor X, Aguilar R (1996) Distribution and abundance of fin whales (Balaenoptera physalus) in the western Mediterranean Sea during the summer. J Zool 238:23-34

Gannier A (1997) Estimation de l'abondance estivale du rorqual commun Balaenoptera physalus (Linné, 1758) dans le bassin liguro-provençal (Méditerranée nordoccidentale). Rev Ecol Terre Vie 52:69-86

Gannier A (2002) Summer distribution of fin whales (Balaenoptera physalus) in the northwestern Mediterranean Marine Mammals Sanctuary. Rev Ecol Terre Vie 57: $135-150$

Gannier A, Praca E (2007) SST fronts and the summer sperm whale distribution in the north-west Mediterranean Sea. J Mar Biol Assoc UK 87:187-193

Gauffier P, Verborgh P, Andreu E, Esteban R, Medina B, Gallego P, de Stephanis R (2009) An update on fin whales (Balaenoptera physalus) migration through intense maritime traffic in the Strait of Gibraltar. Int Whaling Comm SC/61/BC6, Madeira

Gauffier P, de Stephanis R, Verborgh P, Esteban R (2011) Fin whales and collisions in the Strait of Gibraltar. European Cetacean Society, Cadiz

Hoyt E (2005) Marine protected areas for whales, dolphins, and porpoises: a world handbook for cetacean habitat conservation. Earthscan/James \& James, London

Ingram SN, Walshe L, Johnston D, Rogan E (2007) Habitat partitioning and the influence of benthic topography and oceanography on the distribution of fin and minke whales in the Bay of Fundy, Canada. J Mar Biol Assoc UK 87:149-156

IPCC (Intergovernmental Panel on Climate Change) (2007) Impacts, adaptation and vulnerability. Contribution of Working Group II to the Fourth Assessment Report of the Intergovernmental Panel on Climate Change. Parry ML, Canziani OF, Palutikof JP, van der Linden PF, Hanson CE (eds) Cambridge University Press, Cambridge

IWC (International Whaling Commission) (2007) Ship strikes working group, second progress report to the conservation committee (IWC/59/CC3), 59th annual meeting of the International Whaling Commission. International Whaling Commission, Cambridge

Jahoda M, Lafortuna CL, Biassoni N, Almirante C and others (2003) Mediterranean fin whale's (Balaenoptera physalus) response to small vessels and biopsy sampling assessed through passive tracking and timing of respiration. Mar Mamm Sci 19:96-110

> Jaquet N, Gendron D (2002) Distribution and relative abundance of sperm whales in relation to key environmental features, squid landings and the distribution of other cetacean species in the Gulf of California, Mexico. Mar Biol 141:591-601

Johnston D, Thorne L, Read A (2005) Fin whales Balaenoptera physalus and minke whales Balaenoptera acutorostrata exploit a tidally driven island wake ecosystem in the Bay of Fundy. Mar Ecol Prog Ser 305:287-295

Laist DW, Knowlton AR, Mead JG, Collet AS, Podesta M (2001) Collisions between ships and whales. Mar Mamm Sci 17:35-75

Laran S, Gannier A (2008) Spatial and temporal prediction of fin whale distribution in the northwestern Mediterranean Sea. ICES J Mar Sci 65:1260-1269 
Laran S, Delacourtie F, Di Fulvio T, David L, Di Méglio N, Monastiez $\mathrm{P}$ (in press). Synthèse sur la distribution des cétacés dans le Sanctuaire PELAGOS et les eaux adjacentes, mise en relation avec leur environnement. Sci Rep Port-Cros Park 26

Le Fèvre J (1986) Aspects of the biology of frontal systems. Adv Mar Biol 23:163-299

Littaye A, Gannier A, Laran S, Wilson JPF (2004) The relationship between summer aggregation of fin whales and satellite-derived environmental conditions in the northwestern Mediterranean Sea. Remote Sens Environ 90:44-52

> Macleod K, Fairbairns R, Gill A, Fairbairns B, Gordon J, Blair-Myers C, Parsons ECM (2004) Seasonal distribution of minke whales Balaenoptera acutorostrata in relation to physiography and prey off the Isle of Mull, Scotland. Mar Ecol Prog Ser 277:263-274

Marini L, Arcangeli A (2010) Changes in cetacean abundance and distribution over 20 years along a transregional fixed line transect in the central Tyrrhenian Sea. In: European research on cetaceans, Vol 24. G.J. Pierce, E. Philips \& R. Lick, Stralsund, p 18-21

Matlab (2006) Matlab R2006a, The language of technical computing. MathWorks Inc., Natick, MA, USA

Mayol P, Beaubrun P, Capoulade F, Mugnier P (2008) Whale-ship collisions: work and outlook from a team in the Pelagos Sanctuary. The example of the REPCET project. In: Proceedings of the 60th meeting of the International Whaling Commission (IWC/60/CC9rev-Agenda item 4). IWC, Santiago

McGehee DE, Demer DA, Warren JD (2004) Zooplankton in the Ligurian Sea: Part I. Characterization of their dispersion, relative abundance and environment during summer 1999. J Plankton Res 26:1409-1418

Mendes S, Turrell W, Lütkebohle T, Thompson P (2002) Influence of the tidal cycle and a tidal intrusion front on the spatio-temporal distribution of coastal bottlenose dolphins. Mar Ecol Prog Ser 239:221-229

Monestiez P, Dubroca L, Bonnin E, Durbec J, Guinet C (2006) Geostatistical modelling of spatial distribution of Balaenoptera physalus in the northwestern Mediterranean Sea from sparse count data and heterogeneous observation efforts. Ecol Modell 193:615-628

Nelder JA, Mead R (1965) A simplex method for function minimization. Comput J 7:308

Notarbartolo di Sciara G (2007) Guidelines for the establishment and management of Marine Protected Areas for cetaceans. UNEP (DEPI) MED WG 308, UNEP, Geneva

> Notarbartolo di Sciara G, Zanardelli M, Jahoda M, Panigada S, Airoldi S (2003) The fin whale Balaenoptera physalus (L. 1758) in the Mediterranean Sea. Mammal Rev 33: 105-150

Nottestad L, Ferno A, Mackinson S, Pitcher T, Misund OA (2002) How whales influence herring school dynamics in a cold-front area of the Norwegian Sea. ICES J Mar Sci 59:393

Olson DB, Hitchcock GL, Mariano AJ, Ashjian CJ, Peng G, Nero RW, Podesta GP (1994) Life on the edge: marine life and fronts. Oceanography (Wash DC) 7:52-60

Palsbøll PJ, Bérubé M, Aguilar A, Notarbartolo di Sciara G, Nielsen R (2004) Discerning between recurrent gene flow and recent divergence under a finite site mutation model applied to North Atlantic and Mediterranean Sea fin whale (Balaenoptera physalus) populations. Evolution 58:670-675

Panigada S, Notarbartolo di Sciara G, Zanardelli Panigada M, Airoldi S, Borsani JF, Jahoda M (2005) Fin whales summering in the Ligurian Sea: distribution, encounter rate, mean group size and relation to physiographic variables. J Cetacean Res Manag 7:137-145

Panigada S, Pesante G, Zanardelli M, Capoulade F, Gannier A, Weinrich MT (2006) Mediterranean fin whales at risk from fatal ship strikes. Mar Pollut Bull 52:1287-1298

> Panigada S, Zanardelli M, MacKenzie M, Donovan C, Mélin F, Hammond PS (2008) Modelling habitat preferences for fin whales and striped dolphins in the Pelagos Sanctuary (western Mediterranean Sea) with physiographic and remote sensing variables. Remote Sens Environ 112: 3400-3412

Panigada S, Capoulade F, Castellote M, Leaper R, Mayol P (2010) Fin whales: progress report on the evaluation of ship strikes in the ACCOBAMS area and protocol to assess ship strikes. Document SC6-Doc 11, ACCOBAMS Scientific Committee

Panigada S, Lauriano G, Burt L, Pierantonio N, Donovan G (2011) Monitoring winter and summer abundance of cetaceans in the Pelagos Sanctuary (northwestern Mediterranean Sea) through aerial surveys. PLoS ONE 6:e22878

Rebetez M, Mayer H, Dupont O, Schindler D, Gartner K, Kropp JP, Menzel A (2006) Heat and drought 2003 in Europe: a climate synthesis. Ann For Sci 63:569-577

Royer F, Fromentin JM, Gaspar P (2004) Association between bluefin tuna schools and oceanic features in the western Mediterranean. Mar Ecol Prog Ser 269:249-263

Sammari C, Millot C, Prieur L (1995) Aspects of the seasonal and mesoscale variabilities of the Northern Current in the western Mediterranean Sea inferred from the PROLIG-2 and PROS-6 experiments. Deep-Sea Research I 42:893-917

> Store R, Kangas J (2001) Integrating spatial multi-criteria evaluation and expert knowledge for GIS-based habitat suitability modelling. Landsc Urban Plan 55:79-93

> Stuart V, Platt T, Sathyendranath S (2011) The future of fisheries science in management: a remote-sensing perspective. ICES J Mar Sci 68:644-650

Tarling GA, Ensor NS, Fregin T, Goodall-Copestake WP, Fretwell P (2010) An introduction to the biology of northern krill (Meganyctiphanes norvegica Sars). Adv Mar Biol 57:1-40

> Tynan CT (1998) Ecological importance of the southern boundary of the Antarctic Circumpolar Current. Nature 392:708-710

Ullman DS, Cornillon PC (2000) Evaluation of front detection methods for satellite-derived SST data using in situ observations. J Atmos Ocean Technol 17:1667-1675

Valavanis VD, Pierce GJ, Zuur AF, Palialexis A, Saveliev A, Katara I, Wang J (2008) Modelling of essential fish habitat based on remote sensing, spatial analysis and GIS. Hydrobiologia 612:5-20

Watkins WA, Moore KE, Sigurjonsson J, Wartzok D, Notarbartolo di Sciara G (1984) Fin whale (Balaenoptera physalus) tracked by radio in the Irminger Sea. Rit Fiskideildar 8:1-14

Woodley TH, Gaskin DE (1996) Environmental characteristics of North Atlantic right and fin whale habitat in the lower Bay of Fundy, Canada. Can J Zool 74:75-84

Würtz M (2010) Mediterranean pelagic habitat: oceanographic and biological processes, an overview. IUCN, Gland, Switzerland and Malaga, Spain

Zane L, Patarnello T (2000) Krill: a possible model for investigating the effects of ocean currents on the genetic structure of a pelagic invertebrate. Can J Fish Aquat Sci $57: 16-23$ 